\title{
ENTERPRISES DEVELOPMENT: MANAGEMENT MODEL
}

\author{
Lina Shenderivska' ${ }^{1}$ Olga Guk ${ }^{2}$ \\ National Technical University of Ukraine "Igor Sikorsky Kyiv Polytechnic Institute", Ukraine
}

\begin{abstract}
The paper's purpose is to provide recommendations for the effective managing the companies'development taking into account the sectoral key elements' transformation. Methodology. The enterprise profits' econometric simulation is conducted to determine the most significant factors influencing their development. According to the model testing result, their multicollinearity was revealed. To get rid of the multicollinearity phenomenon from the profit models, isolated regressors are excluded, namely, return on assets, material returns, return on equity. To obtain qualitative models with a small error of model parameters estimation and, accordingly, high reliability of the conclusion about the interrelation between the factors of the model and the resulting feature, factors in the income model that are not closely interconnected, that is, not multicollinear, are included. Determination coefficients $\mathrm{R}^{2}$ and F-criterion were calculated for model quality checking. The modern printing enterprises of Ukraine key elements, connected with integration into the global information space, are analysed. Results. The interrelation between a company's development and earning capacity is identified in the study. The profit importance as the main source for enterprise financing is substantiated. Factors that have the greatest impact on the enterprises' development are labour productivity, financial autonomy, working capital turnover, and the character of their influence is most adequately reflected by the power model. Peculiarities of the enterprises' activity include increased competition at the inter-branch level, poorly developed industrial relations, and the own sources of financing activities shortage. Practical implications. Based on information on the most significant developmental impact factors, directions for perspective enterprises development for their competitiveness increase are proposed: diversification based on the activity expansion, the enterprises' organizational structure change, investment development. The actuality of diversification's activity for profit increase due to new markets development is determined. It was found that corporations are the most acceptable organizational form for the enterprise. The urgency of investment development for printing companies is proved connected with the production modernization's necessity, ensuring the manufacture of competitive products. Value/originality. To ensure the effective enterprises' development based on development concept, a model for managing the printing companies' development is worked out. The model for managing the companies' development is prepared based on the concept that takes into account the peculiarities of enterprise activity and priority directions of their development, improves the directions for enterprises adaptation understanding in the competitiveness growth conditions.
\end{abstract}

Key words: earning capacity, profit, development, investment development, concept, management model.

JEL Classification: E22, L11, M11, O20

\section{Introduction}

In modern conditions, an aim prerequisite for enterprises functioning is their development, associated with different approaches to its essence. At the heart of the development process is considered the state of the economic system; various types of changes that determine development; diversity of inter-linkages between the factors of all the enterprise's environments. The enterprise as an object of management gets functions that influence its development, including strategic ones, and is a constant search for development and economic growth directions associated with economic changes. Enterprises development is first qualitative changes in its activities and conditions (Hvostina, 2015). Earning capacity of the enterprise is determined by the social and economic earning capacity level, requires a work's motivation, a work's management, a working conditions creation, an enterprise infrastructure development, environmental preservation. All this is important both for product quality and its competitiveness. According

\footnotetext{
Corresponding author:

${ }^{1}$ Department of Management in Publishing and Printing Industry, National Technical University of Ukraine "Igor Sikorsky Kyiv Polytechnic Institute".

E-mail: lina.shenderivska@gmail.com

${ }^{2}$ Department of Management, National Technical University of Ukraine "Igor Sikorsky Kyiv Polytechnic Institute".

E-mail: olgaguk@ukr.net
} 
to many scientists, social, economic, and environmental development (Bhattacharya et al., 2015; Klapper et al., 2016; Satterthwaite, 1997) are integrated into sustainable development concept. Environmental factors, in turn, impact economic growth, and the demographic situation, birth rate (Varvarigos et al., 2017).

The authors focus on the study of factors affecting the enterprises' development, justifying the business development ways, prove the state support urgency for small and medium enterprises.

Enterprises development is influenced by internal and external factors. The authors substantiated the state policy's importance for the small and medium enterprises development, suggested the actual state policy directions: the financial instruments implementation, information about promising markets dissemination, topical technologies, ways to save costs for the business entity (Taiwo et al., 2012). The state offers a differentiation of support programs for small and medium businesses, distinguishes between the Program for lending to small family businesses, programs for attracting graduates to business, micro-lending programs for the unemployed to start their business, long-term loans (5-10 years) to small and medium enterprises at a very low interest rate (Oni, 2012). Eversole (2004) argues the micro-enterprises role fight poverty, and self-sufficiency of these enterprises owners to improve their conditions. The clusters creation is important for small and medium-sized enterprises development, but this process is complicated over the lack of cluster sizes to compete globally, the lack of resources, an insufficient infrastructure, and the lack of training for cluster managers (Lopriore, 2009). Conditions for the effective Governance in associations are accountability, transparency, consistency, and participation (Nwankwo et al., 2012).

Thus, to a deeper insight in small business enterprises development processes, Butler (2006, p. 221) substantiates the typical phases of business development: the initial start-up phase of a new business, the relative stability, the growth and the development, and the need to use different business models for each of these stages. Butler (2006, p. 223) proves the gradual delegation of authority topicality, the transition from concentration to operational activity to strategic thinking, the constant acquisition of relevant knowledge and skills that will contribute to long-term growth and the business sustainability; also provides a recommendation for enterprise managers to apply those management principles proper to the business size.

In the paper (Asian Productivity Organization, 2007), according to the competitive impact on development, such indicators as effective business models and strategies allowing to enter new markets, aspirations for leadership, an investment activity, and an innovation, are identified. Promising areas for small and medium-sized businesses development are defined by a partnership with large companies, entrepreneurship. The work (Durowoju, 2014) also justifies the entrepreneurship's priority, since it can provide long-term competitive advantages. A generalization is made that companies should create entrepreneurial networks for coaching, mentoring in their work (Asian Productivity Organization, 2007). Thus, the researchers are the adherents of the competition concept as a partnership, allowing achieving global benefits for the market.

Development is associated with changes that offer some opportunities for economic growth and create operational risks. Companies that implement breakthrough innovations are at the highest risk, as opposed to evolutionary innovations, as they create new markets (Goutam et al., 2015). The competition growth impacts on development, therefore, there is a need for continuous management's improvement by product quality upgrading, the production costs cutting and the business risks reduction. Every effective enterprise should offer an innovative product and develop a business model (Teece, 2010).

The latest technologies adoption ensures the betterquality products production, production operability, productivity gain, and resource intensity reduction. In (Sacala, 2014) justified the modern information technology application in enterprise management, identified the actual principles for constructing the enterprise architecture - the ability to adapt to changes, build an efficient resource management system, use the Internet possibilities to integrate into the global market space. The current trend in information technology's development is applications. Authors (Unhelkar et al., 2010) argue the relevance of applications that integrate or isolate basic functions relevant to consumers, contact groups, business management, such as mobile broadcast, information, transaction, operation, and collaboration for enterprise development, namely, meeting new consumer needs, operational activities effective implementation, raising the competitiveness level. Surugiu (2012) justifies the integrated information system usage importance due to such advantages as an accelerating data processing, a speeding-up data in real time, an optimizing the control of business costs distributed on cost centre.

The amount of investment affects the qualitative and quantitative increase of economic value added, invents innovation activity. In (Ricupero et al., 2001), the sufficient financing for effective actions significance and the competitiveness achievement in global markets has been proven. Limited access factors to credit resources are substantiated. The progressive experience of the European Union countries in overcoming the barriers in getting loans was established through the creation by small and medium-sized enterprises of Mutual Guarantee Society, funded by its participants and provides financial guarantees to enterprises at their request to banks for getting credit funds. Funds 
providing financial guarantees are successfully operating in France, Italy, Spain, and Germany.

The financing enterprise development issue is also explored by Luiz (2000) and proves that growth in production a beneficially influences the credibility of debtees; the orders inflow can be furnished through the participation in tenders for state procurements, the sales networks development, implementation of technical and organizational decisions aimed at increasing in labour productivity (Luiz, 2000).

Thus, speeding-up scientific-and-technological progress, changing market conditions, the need to find sources of investment resources and directions for their efficient use raises theoretical and practical interest in the enterprises' development. In the development management process, it is necessary to strain after balanced improvement of all enterprise subsystems.

Increasingly relevant in present-day conditions of domestic economy's development becomes the development management for printing companies, due to their importance to society to meet its information needs and to ensure access to quality printing products, and several features, such as the predominantly smallscale business, affiliation with publishing activities, a high level of printing equipment cost, material content, import dependence.

With the urgency of the enterprises' development problem to ensure their earning capacity and competitiveness, the authors put and executed the following research objectives:

1) current trends in the printing companies in Ukraine development are described;

2) the interrelation between development and earning capacity of the enterprise is substantiated;

3 ) ways of increasing the enterprise earning capacity development are determined;

4) the management model for enterprises development to ensure their competitiveness in the market in presentday conditions is worked out.

\section{Influence of development on increasing the printing enterprises earning capacity activity}

The printing industry enterprises activity is commercial, enterprises are aimed at a profit, and their specialization in the works execution to order all economic branches, in particular, the replication of periodical and non-periodicals, promotional materials, packaging, labels, blanks, etc., forms a significant potential for development. Publishing products (books, newspapers, magazines) accompanying people in learning, work, recreation, development, forming its outlook, the level of culture, patriotism, depth and breadth of knowledge, education, competence, thus, the level of self-awareness and the nation's intellectual potential are formed and developed, affects the human welfare of the population, as a consequence, the country's reputation. And in conditions of preservation, multiplication and productive use of the nation's intelligence, an effective socio-economic development of the country takes place and its contribution to world progress is ensured.

Other types of printing products, for which the information function is determinant as well, are also important. Thus, the attended printed matter provides the commodity producers with necessary information about the product; packaging is a necessary element in supply logistics, stationery, despite the electronic media's expansion, are irreplaceable in creating a corporate culture and style; markings provide effective, relevant navigation, promotional materials serve as information in specific places and time, and so on. Such products variety ensures the printing industry's integration with all spheres of production and human activity.

The printing industry is a part of publishing and printing complex since its activities are impossible without the information products or editions manufacture. Thus, the printing products market is a part of the information market, which in present-day conditions is characterized by the communications complication in the information space, the products distribution and sales forms diversification, increased market volumes and increased differentiation, transformations in the culture of information consumption, which requires effective strategizing of publishing and printing enterprises development. The printed publishing products manufacturers, integrated into the media market, compete not only with traditional producers of information - radio and television but also with manufacturers, operating on Internet platforms these are social networks, Internet TV, mass media, presented on the Internet, electronic, audio editions, blogosphere, mobile applications, Telegram channels, online educational courses and more.

The publishing market's structure is closely linked to the economic development level, the education and culture level, on which the level of demand depends and, therefore, the economic status, investment opportunities of publishing and printing enterprises. Increase in demand for information products in nonlegible form raise the investment attractiveness of their manufacturers level and leads to a partial capital outflow from manufacturers of traditional printing products, in these conditions, both the publishing and printing companies' innovation development and the need for state support grows are important. Granting tax exemptions, increasing the state orders volume, public investment in scientific and technical support will promote an effective reproductive policy in the industry, and thus attainment the European standards level of development.

We have analysed the books and brochures output dynamics in Ukraine to determine the production floor trends for 2011-2015 (Figure 1). 


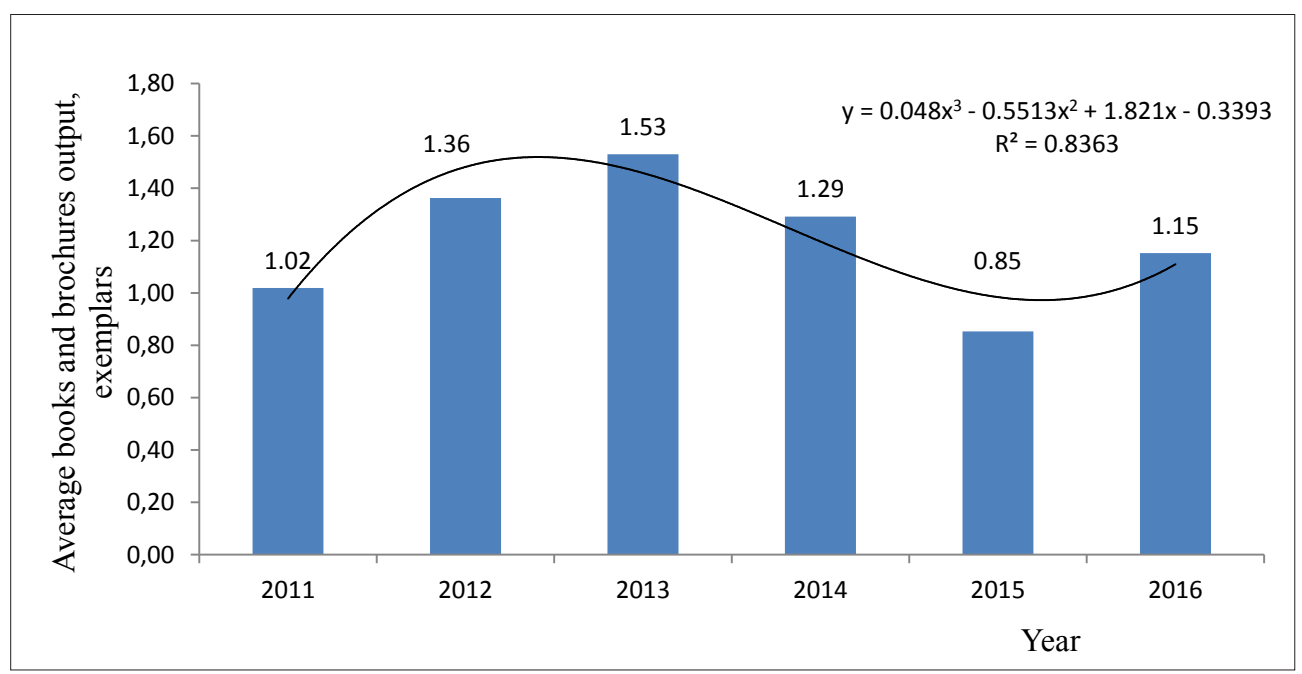

Fig. 1. Dynamics of average books and brochures output per one resident of Ukraine (exemplars) for 2011-2016

Source: Statistical information of the State Statistics Service of Ukraine, built by the author using the MS Excel package

In 2014-2015, compared with 2013, the tendency was shown to reduce the average books and brochures output and for 2011-2016 this index did not exceed 2 copies, which does not contribute to the full society development. During the analysis, the average circulation did not exceed 2.6 thousand exemplars, and the smallest its value was in $2015-1.82$ thousand copies. Small circulations stimulate printing companies to implement technologies and equipment, alternatives to offset printing, which ensures the earning capacity of small production output. It creates conditions for microenterprises' development, guided by small circulations, and for industry's cooperation development since not all entities are capable of performing a complete technological cycle. As the analysis showed, the share of small enterprises in 2015 was $96 \%$, which determines the peculiarities of the printing industry, namely, the competition high level, the shortage of resources for development.

The earning capacity of development is influenced by enterprises' innovative activity. Based on a certain share of innovative products in the printing industry from 2011 to 2016, the maximum value of the innovative products' share was $2.01 \%$ in 2012 ; the minimum is $0.55 \%$ in 2015 . This is due to the insufficient financing of enterprises. During this period, in the total volume of printing products, the newspapers' share decreased from 7 to $4 \%$, as the number of newspaper producers decreased by $30 \%$.

To ensure earning capacity of publishing activities, a well-established system of interaction between partners is required, which, as the analysis showed, changes in the current period, complemented by the progressive communication tool advancement - the Internet, which affects the earning capacity printing companies' development. In the unfavourable market conditions context, it is necessary to look for ways to preserve the volumes of production and sales, increase the volume of profit as the main source of development.

To determine the internal factors' influence on the enterprises of the sector activity, we have constructed the net profit econometric models for six printing enterprises (Table 1). The enterprises are chosen according to the following criteria: the enterprises' size, the products' range, the completeness of the production cycle - pre-print, printing, and post-printing stages, experience in the market.

Factors in the model are the labour productivity $\left(\mathrm{x}_{1}\right)$, the financial autonomy coefficient $\left(\mathrm{x}_{2}\right)$, the working capital turnover $\left(\mathrm{x}_{3}\right)$. The obtained power models of

Table 1

Net profit econometric models for enterprises

\begin{tabular}{|l|c|}
\hline \multicolumn{1}{|c|}{ Enterprise } & Net profit econometric model \\
\hline LLC “BVI-Print" & $\mathrm{y}^{*}=0.169 \mathrm{x}_{1}{ }^{1.27} \mathrm{x}_{2}{ }^{-0.789} \mathrm{x}_{3}{ }^{0.614} ; \mathrm{R}^{2}=0.9510 ; \mathrm{F}$ true $=181.108$ \\
\hline LLC “Vistka" & $\mathrm{y}^{*}=13.057 \mathrm{x}_{1}{ }^{-0.387} \mathrm{x}_{2} \mathrm{x}^{0.794} \mathrm{x}_{3}{ }^{2.569} ; \mathrm{R}^{2}=0.834 ; \mathrm{F}$ true $=46.945$ \\
\hline LLC "Macros" & $\mathrm{y}^{*}=70.869 \mathrm{x}_{1}{ }^{0.472} \mathrm{x}_{2}{ }^{-0.21} \mathrm{x}_{3}{ }^{0.031} ; \mathrm{R}^{2}=0.773 ; \mathrm{F}$ true $=31.901$ \\
\hline LLC "Mega-Poligraph" & $\mathrm{y}^{*}=14.67 \mathrm{x}_{1}{ }^{0.989} \mathrm{x}_{2}{ }^{-0.334} \mathrm{x}_{3}{ }^{0.057} ; \mathrm{R}^{2}=0.914 ; \mathrm{F}$ true $=98.787$ \\
\hline LLC "Avanpost and Partners" & $\mathrm{y}^{*}=11.187 \mathrm{x}_{1}{ }^{1.008} \mathrm{x}_{2}{ }^{-0.092} \mathrm{x}_{3}{ }^{0.115} ; \mathrm{R}^{2}=0.906 ; \mathrm{F}$ true $=90.394$ \\
\hline LLC “Univest Marketing” & $\mathrm{y}^{*}=5.872 \mathrm{x}_{1}{ }^{1.242} \mathrm{x}_{2}{ }^{-0.025} \mathrm{x}_{3}{ }^{0.711} ; \mathrm{R}^{2}=0.9169 ; \mathrm{F}$ true $=102.955$ \\
\hline
\end{tabular}

Source: Self-developed 
net profit manage the economic content of the CobbDouglas production function, where the indicator of labour resources (L) and capital (K) are used as independent variables. To adapt the Cobb-Douglas function to the functioning of domestic enterprises conditions, we propose to express the labour resources category as an indicator of labour productivity, while the capital category is an indicator of its structure (financial autonomy coefficient) and the efficiency of capital use indicator (working capital turnover).

Based on the obtained power models of net profit comparison with the Cobb-Douglas production function, it is determined that they are similar in economic terms.

To a greater extent, the profit of LLC "BVI-Print" is influenced by labour productivity, which is determined based on the elasticity coefficient, whose value is 1.27 , with the increase in labour productivity by $1 \%$, the growth rate of net profit is equal to $1.27 \%$, and the smallest impact of labour productivity on profit at LLC "Vistka" is 0.378 . For all investigated enterprises, in addition to LLC "Vistka", the negative value of the elasticity coefficient for the indicator of autonomy is defined, with the share of equity capital increase in returns of profit decreases. The elasticity coefficients, determined for the working capital turnover factor, in all enterprises is positive, prevails on the level of elasticity of LLC "Vistka" - 2.569, a less noticeable effect of working capital turnover on profit at LLC "Macros" - 0.031 .

Taking into account the priority of increasing labour productivity to increase the profit of enterprises, the urgent tasks are an expansion of printing enterprises markets both at the expense of orders' physical growth and more qualitative satisfaction of consumers' needs, and also updating of the enterprises' technical equipment. These measures are necessary not only to increase the cash revenues volume of enterprises but also to avoid financial losses.

\section{Directions to increase the earning capacity of enterprises development}

Substantiation of the earning capacity directions of enterprises development depends on their current state, promising sales markets, industry practices, strategic orientation of enterprises, state policy in the industry, the relevance of a new cooperation forms development. The authors of the article defined such promising directions of development for printing enterprises:

- the enterprises' activity diversification;

- the enterprises' organizational structure change based on their corporatization;

- investment development.

The need for comprehensive customer satisfaction, the search for new, more profitable sales markets, and the scientific and technological progress implementation are justified by the diversification expediency of enterprises activity based on its expansion.

When choosing the enterprise's diversification, the expected earning capacity and its duration must be considered. Diversification allows solving several tasks for the enterprise, namely, profits increase, operational risks reduction, the increase of capacity utilization, intellectual potential of enterprise, efficient use of investment resources. Diversified enterprises are characterized by a lower level of profit volatility (Pandya et al., 1998).

The management of diversification process organization requires the solution several tasks, namely: - management organizational structure achievement compliance with tasks to be solved with an allowance for activity expansion;

- possibilities of optimization of diversification processes estimation at the enterprise by the rational allocation of functions, implementation of outsourcing and outstaffing practice in practice;

- effective motivation system application.

Improvement of management organization is occurring due to the program-target organizational structures of management implementation, quality management systems, which promotes the quality improvement, products competitiveness, a rise in profitability.

The employees' functions expansion requires an appropriate remuneration, which should be taken into account by motivation system. Therefore, to build an effective motivation system, it is necessary to set fringe benefit expanding functions in the conditions of diversification, to provide high-quality communications by informing employees about the system of incentives and charges. Bloom et al. (2010) to progressive incentive systems refers the employees' participation in profits distribution.

To increase the earning capacity of enterprises activity, we offer a better organization form, such as corporatization, based on their activity's diversification and their own investment sources. In present-day conditions, participants in the publishing and printing complex are inefficiently productively interacting, thus not fully exploiting the potential of economic growth. Publishers, without paying due cognizance to the study of demand, prefer the rights purchase to translate world bestsellers, which check the growth of the domestic copyright environment. To save money, publishers organize product sales on their own, and it is expedient to delegate it to wholesale booksellers, which will help to reach a promising sales chain - network supermarkets. Printing enterprises cooperate insufficiently with publishers at the technical publications preparation stage, which adversely influences product quality, cost, and price. Book trade organizations pay insufficient attention to the stock management, do not interact with publishers for the purpose of studying the demand for 
book products. Corporatization will aid in improving the publishing and printing enterprises interaction, thus, better satisfying the consumers' needs, as an increased competitiveness consequence, earning capacity of development.

The need for business consolidation is due to two factors: the lack of own financial resources for large-scale production and technology projects and the limited target markets capacity (Kobernyk, 2012). The main motives for the corporations' creation are the search for ways to increase the earning capacity of business operation, promising investment's directions, market's expansion. Based on certain motives, the structure of potential participants is substantiated, it is expedient to attract those partners who will strengthen or expand the competitive advantages of the association and will provide an economic earning capacity. It is advisable for printing enterprises to form associations with publishers with highly qualified personnel, commercially successful publishing projects, a significant market share, publishers which apply innovative technologies, provide high-quality products, and focus on consumer inquiries. Bookselling establishments, preferably network or wholesale with a broad sales geography and a payment discipline high level may be involved in corporations, which will help reduce sales costs and speed up a capital turnover.

Determining the goal, setting tasks for corporations is based on the results of the external and internal environment analysis, allowing showing the competitive advantages of enterprises, the possibility of their implementation, and sizing the prospects for further market development. The purpose of corporations is justified based on current and future conditions of development and is defined as the profit's growth, the preservation or gain of market share, the new markets' creation.

Companies taking part in the corporations will maintain their legal independence, required since the peculiarities of publishing and printing companies, which have their own material and technical base and market. Integrating the participants of the corporation involves observing such fundamental propositions as common economic rules, real investments, joint creation, and resources application.

The uniform rules in corporations, first, need to be established about the price and services payment provided by the participants.

The association has additional opportunities for setting discounts on prices since placing orders on one production facility contributes to a reduction in fixed costs, and a price discount is determined in proportion to the amount of expenses saved.

The enterprises' unification within the corporation into a single online platform with further centralized orders distribution taking into account the specialization, technical capabilities, and the enterprises logistics level, allows to meet demand effectively and optimize costs, thus to volume own investment sources.

In the enterprises' context unification, conditions to improve the products quality arise. Development of the quality management system is a task of strategic management level, and the formal implementation of quality standards does not guarantee the earning capacity of the quality management system (Zajarskas et al., 2010). The products quality is determined by the components, parameters, subjects of quality assurance (Figure 2).

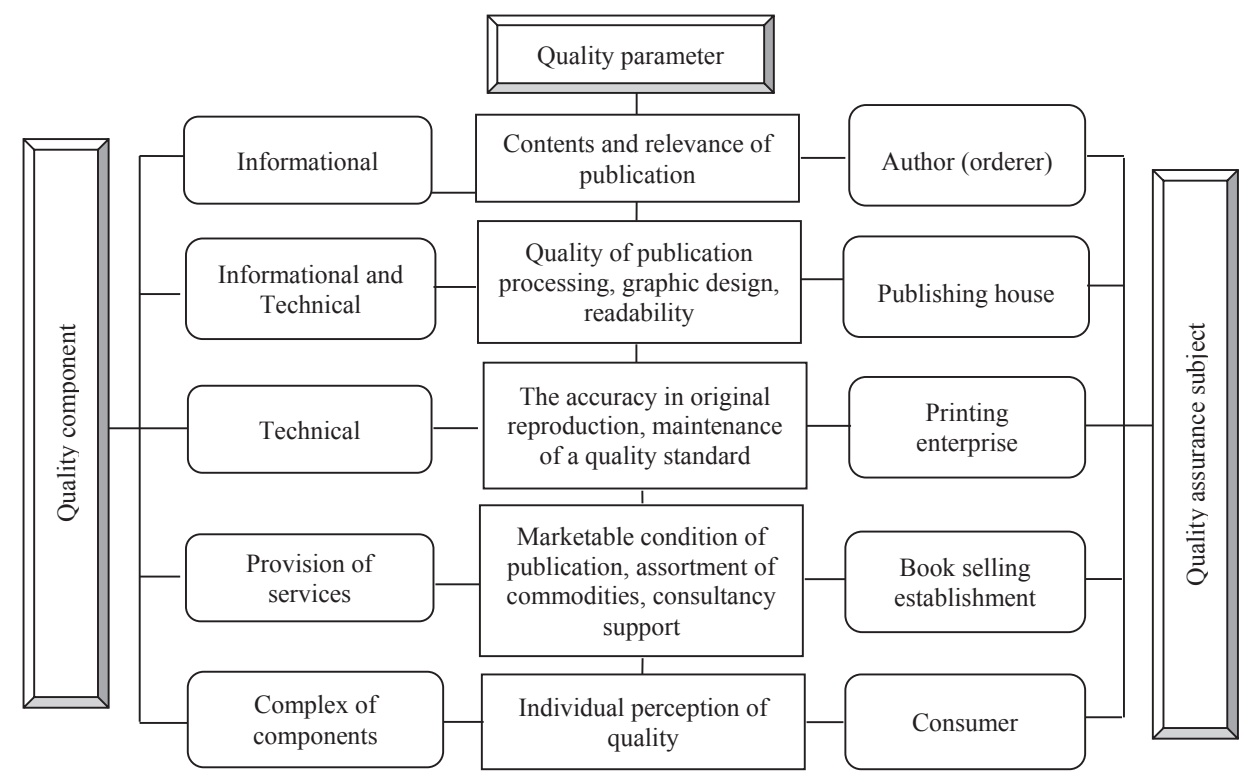

Fig. 2. The essence of publishing products quality components Source: Self-developed 
An important role in the demand's generation and publishing products consumption culture belongs to the quality assurance subject. These are customers (authors) or publishers, who must provide relevant content and a quality presentation of textual and graphical information. Quality also depends on the technical parameters projected by publishers and embodied by printing companies in the edition size, taking into account product quality standards. Final purchasing decision is taken by consumers with a glance to the quality publications parameters, provided by the ordering customers (authors), publishers, printing enterprises, and the booksellers' service level, respectively, consumers take into account general parameters and individual perceptions of quality.

When creating an enterprises' association, it is advisable to centralize the quality management function, which will encourage maintaining the common high standards of work and craft a positive image of the corporation. In the corporation, to avoid functions duplication, it is expedient for publishing-members of associations to delegate to printing companies the power to choose printing materials suppliers, to determine the rational stock size, which will save on specific costs.

Another aspect of improving the earning capacity of enterprise development is investment development. As analysis shows, investment development depends on several factors, with the directions of activation of investment activity are determined. These factors include the funding ratio of own sources, the cost of debt, the enterprises' development state, the material and technical base level.

Measures aimed at intensifying investment activity identified innovation as investment, product quality improvement, enterprises investment attractiveness upgrade, development of organizational forms of fixed assets use (lease, financial leasing, etc.), amortization usage for functional purposes, rational formation and funding sources use.

The investment development of enterprises planning requires determination of investments sources return, the main of which are amortizations, net profit, financial expenses. Considering that the loan rate, leasing rate are compensated at the expense of the enterprise, the principal bank loan payment is carried out at the expense of net profit, and the leasing agreement provides for an additional source for compensation - amortization, so leasing increases the earning capacity of investment, as it contributes to reducing payback, compared with a bank loan.

\section{Management model for enterprises development}

Management for enterprises development requires appropriate levels of information, resource, and organizational support. At the information support level of management for development, an analysis of the enterprise's state and the external environment is carried out. The functions of information provision include the necessity determination for changes, setting goals and tasks of management for development. At the second level, for rational resource provision, applications are being developed and implemented to improve the earning capacity of delivery and consumption processes. The third level - organizational support - involves an organizational structure's construction and, on its basis, management functions, taking into account such system development of labour motivation, which will contribute to achieving the goal of management for enterprises development. According to Shchekovych et al. (2013), in the process of management for development, monetary, non-monetary, social goals are achieved.

The earning capacity of management for enterprises development depends on the prospects of activities that are associated with the strategic directions establishment for their development. At the heart of modelling process of management for development is the concept of printing enterprises development. Concept formulation of enterprise development involves their activities goal determination and the tasks for achieving it, substantiating directions of effective enterprises development.

In unstable market conditions, as analysis shows, the printing enterprises' priority tasks are stabilization of production output and profit, the market share preservation, the product quality level, and the personnel turnover reduction. The clear strategic priorities of enterprises definition contribute to their effective development.

We have defined the main provisions of the printing enterprises development concept:

- European integration processes and increasing the use of existing production capacities based on meeting the needs of the domestic market and enhancing foreign economic activity;

- production and certification organization under international quality standards;

- modern information technologies introduction for accelerating the orders receiving process and production cycle;

- raising the enterprises' innovation activity level based on production modernization;

- production tides between publishing and printing enterprises expansion, and connections within a broader structure to increase the earning capacity of activity; - increasing the ecology in present-day conditions value, which stimulates environmentally safe materials, reducing of waste production;

- personnel deficiency of adequate qualification level reduction, which is explained by the rapid change of technologies in the enterprises' economic activity.

Taking into account the current state of printing enterprises development, it is necessary to reorient 
the tasks of management for development we have identified during the study, namely:

- increasing the competitiveness of printing products, comparing with substitute goods, above all, by the price index, explained by the tendency to increase the share of information distributed in electronic form;

- strengthening of the domestic resource base, first, to supply consumable materials and equipment, relevant since the high level of import dependence of printing industry;

- balancing the industry by the scale of enterprises and the level of mechanization and automation under the current market's needs, since the technical and technological potential level of many enterprises is not progressive, and there is also a reserve to reduce the product cost by economies semi-fixed costs;

- increasing the level of the infrastructure of printing development, publishing market and the earning capacity of promotion of printing and publishing products to foreign markets, since a potential for increasing the printing production competitiveness by improving state support systems, public procurement, financing, logistics, integration in the scientific and technical sphere etc.;

- increasing the products consumption culture, necessary to reduce irretrievable waste in the printing products circulation, first, packaging, and reducing environmental pollution with synthetic materials.

Effective implementation of certain tasks for management for printing enterprises development is possible under the following conditions: state support and publishing, printing industry regulations, the publishing and printing industries integration; protection of the domestic market of printing products by the proper competitiveness level of domestic production; taking into account strategic competitive advantages, goods and services that provide maximum profit to the enterprise, thus, the specialization development and co-operation, and minimization or phase-out of products unprofitable types; enterprises innovation activity stimulation; continuous education as a trend towards improving the education quality.

The conceptual management model for development is proposed. The model is based on the example of printing enterprises (Figure 3). At the core of the elaboration is the goal to improve the earning capacity of enterprises activity in present-day conditions of rapid changes at macro and micro levels, and elements identified such as diversification processes, change the organizational structure of enterprises, the whole chain customer-producer-consumer creation and the real investments use.

Diversification processes are aimed at developing new markets, distribution of risks between separate areas of activity, higher use of existing production capacities. It is determined that the diversification implementation requires an integrated approach, namely, the assortment's expansion, new technologies introduction, changes in management.

The diversification type depends on the conditions and objectives of enterprises activity. In the printing industry, it is expedient to diversify in horizontal and mixed directions. Horizontal diversification will allow developing the promising products, services, is actually in the conditions of changing the printing products market structure. The mixed diversification, which will help control the chain of the publishing and printing complex, is of great importance: order-supplyproduction-sales, which will save enterprise costs. In the medium and large enterprises of the printing industry, which have sufficient resources for the new business development that is technologically not related to the main production, conglomerate diversification is possible.

The second direction proposed by the authors is the corporatization of enterprises. It is determined that the enterprises that will form a corporation will not lose their legal independence.

The general principles, on which the companies' cooperation within the corporation will be organized, are substantiated, the criteria for participants' selection are determined. The business associations' creation aims to increase the competitive stability of enterprises through the production scale. The permanent participants' collaboration will provide a phased solution of tasks of higher production capacity use of printing industry, increasing their activity profitability, and for publishers - searching an effective production base for publishing products replication.

In present-day conditions of integration and globalization processes, a rational distribution of limited investment resources is needed, therefore, the authors proposed a direction - investment development of enterprises. Priority should be given to such key areas as technical and technological modernization to ensure the high-quality production and low cost of products, personalized orders, the market expansion for non-corporative consumers; the advanced technologies introduction, in particular, digital printing, to achieve the economic earning capacity of production of small print runs, is an equivalent of current market trends - reducing the products circulation; technical support for printing on difficult surfaces to enter new markets.

Production that is compliant with international quality standards will increase the competitiveness of enterprises and industry, growth in incomes and profits of enterprises allowing increasing financing for production modernization, which will meet the everchanging consumers' needs, thus reaching new strategic markets and gaining growth the capital return level through real investment in innovative development.

The profit is the main indicator, which characterizes the earning capacity of the enterprise activity and 


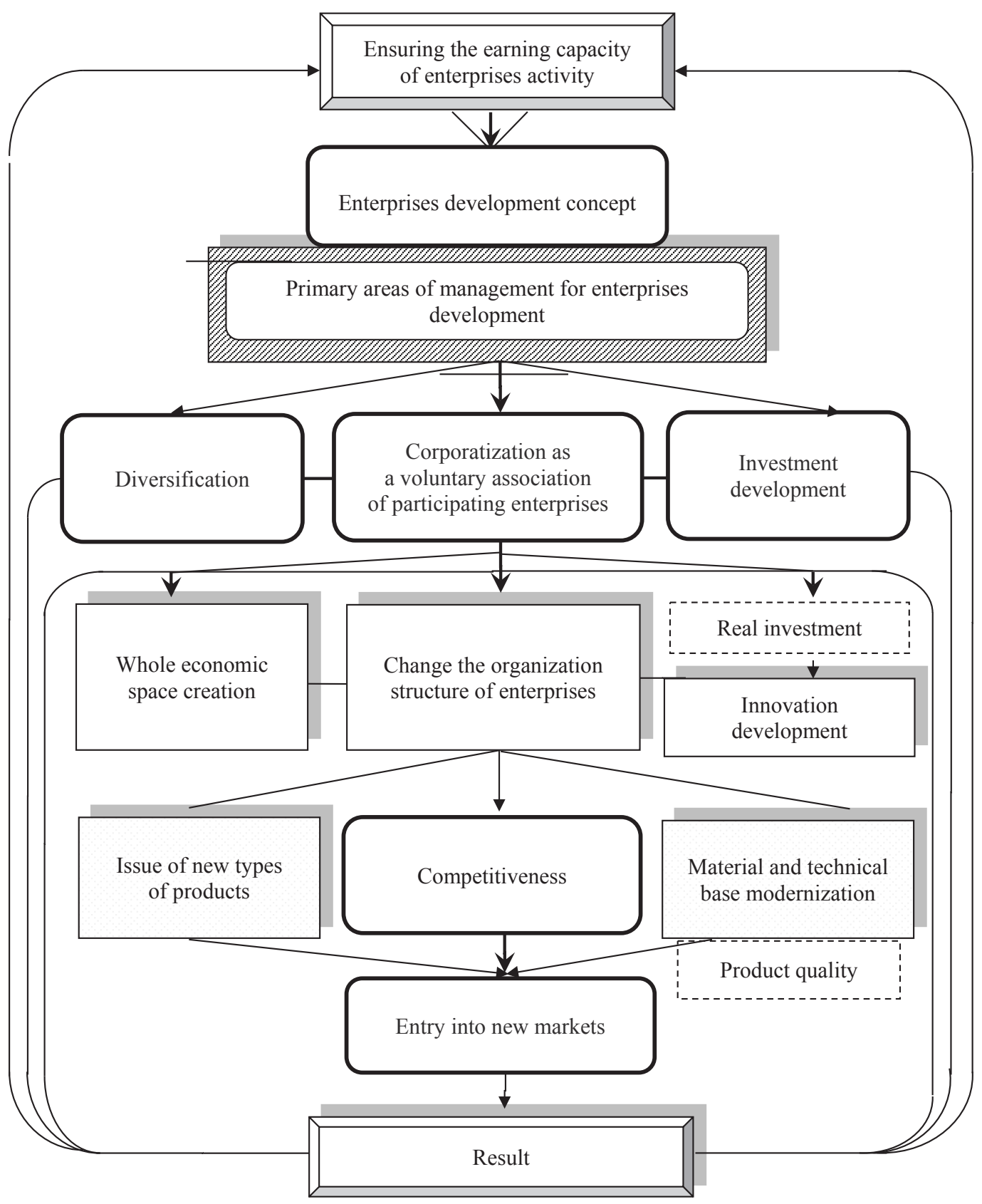

Fig. 3. Conceptual management model for enterprises development

Source: Self-developed

is the main source of development. To determine the prospects of investment development, we have calculated the forecast of the printing enterprises profit based on econometric models. The predicted value of profit decreases. As enterprises do not have enough own sources for financing development and are characterized by a high risk of functioning in conditions of a high level of competition, the objectivity importance in choosing the best investment projects according to technical, economic criteria, etc., increases, thus, on the correct assessment of the investment project at the planning stage, the success of its implementation depends.
We have substantiated the criteria for assessing the earning capacity of investments for enterprises. In determining the economic feasibility of using credit investment resources, an indispensable prerequisite is the higher value of investment return, calculated with profit, without deducting the price of the loan payment, compared with the price of the loan. Sufficient prerequisite is to exceed the return on investment, calculated with a net profit, over the proportion of loan repayment per unit of the investment period. This condition should be taken into account when calculating the market value of enterprises, in particular, by the 
method of economic value added (EVA). Accordingly, the earning capacity assessment of investment is based on absolute indicators such as profit, economic result, net present value, and relative indicators, in particular, investment return, which takes into account the sources of investment return.

The economic earning capacity accounting of the proposed management model for enterprise development performed on the printing enterprise example is typical for the industry because of its small business scale; promotional products profile, which will save on the sale of a new product by offering it to existing customers; is a promising outlook for joining the corporation. For implementing the horizontal diversification strategy, the volume of investments is 400 thousand UAH. The enterprise has a shortage of own financing sources; therefore, is foreseen to conclude a leasing agreement at a price of $16 \%$ per year. The payment to the lesser of the principal of the loan is due to the deprecation cost and $60 \%$ of net profit. The cash flow is discounted, the upper limit of the discount rate, recommended for the economic conditions of Ukraine, is adopted and is $20 \%$ per year. The net present value is calculated:

$$
\begin{aligned}
& N P V=84.6+\frac{86.5}{(1+0.05)}+\frac{88.5}{(1+0.05)^{2}}+\frac{90.5}{(1+0.05)^{3}}+ \\
& +\frac{119.1}{(1+0.05)^{4}}+\frac{121.7}{(1+0.05)^{5}}-400=118.8 \text { thousand UAH. }
\end{aligned}
$$

The project payback period is 1.5 years. For the first year of the project, 240 thousand UAH will be reimbursed, for the next six months - 160 thousand UAH. It is also necessary to paylease price, charged on the balance of the debt, its total amount for 1.5 years is 59.5 thousand UAH. Based on the calculations performed on the printing enterprise example, it is determined that implementing the proposed development directions will ensure an increase in net income of the company by 1410 thousand UAH or $22.3 \%$, a net profit of 270.2 thousand UAH, $33.7 \%$, comparing to the level of the base year, the expenses' profitability will increase by 0.4 percentage points.

The all tasks fulfilment related to the management for printing enterprises development will promote to:

- ensuring the products high competitiveness in the domestic and foreign markets, high productivity and rhythmic production; investment activity intensification;

- corporate culture and the level of labour-management enhancement;

- the enterprises' social image making;

- rational use of resources;

- providing information security of the country.

\section{Conclusions}

The internal and external environments instability causes constant management of changes in enterprises, the effectiveness of which depends on the resources availability, their use efficiency, the achieved state of development. The effective development of enterprises policy is determined by the peculiarities of enterprises development, including the product quality level, demand volume, activity scale, integration processes, investment attractiveness level, etc. Over $90 \%$ of enterprises are small scale, this limits their financing possibilities from their own and attracted sources, reduces the level of operational stability. Printing enterprises carry out orders for corporate and individual customers, and enterprise development requires a clientoriented approach based on meeting the consumers' needs in terms of production and supply efficiency and ensuring product quality.

The analysis of the state and trends of printing enterprises' development showed that the perspective directions of enterprises development are: diversification based on activity expansion, change in the enterprises' organizational structure, investment development. Creation of corporations will be based on an integrated structure for effective achievement of goals and solving common tasks. Creation of corporations, modern methods of work introduction will reduce the production time and receipt of products in the market will help increase its competitiveness, which requires consideration of the life cycle of goods, which in present-day terms is short and depends primarily on demand offer for goods. Increasing the earning capacity of printing enterprises requires their investment development, in which innovation is the main form of investment, and investment development is directed primarily at modernizing the material and technical base of enterprises.

The printing enterprises development concept, which defines the goals, tasks, and directions of small and medium business enterprises development, is proposed. For the successful implementation of the concept, organizational changes to the development management process are required.

Based on of the concept, a model management for enterprise development is proposed, which takes into account the directions of effective management and the peculiarities of the printing industry enterprises and the need for constant and complex adaptation to the external and internal environmental conditions, and is aimed at increasing the earning capacity of activity. The model predicts the commodity producers' corporations creation based on uniform economic rules for all enterprises of the industry.

Additional expenses directed at a complex of directions on management improvement realization for enterprise development amount to 400 thousand UAH. Their expediency is evidenced by the lower estimated payback period of investments - 1.5 years, compared to the normative -5 years, and the positive net present value of 118.8 thousand UAH. 
The enterprises of the industry effective activity will allow realizing all conceptual directions of development, and this will promote working conditions improvement, stimulation of labour, productivity increase, competitiveness of production increase.

\section{References:}

Bhattacharya, A., Oppenheim, J., Stern, N. (2015), Driving Sustainable Development Through Better Infrastructure: Key Elements of a Transformation Program, Washington, DC: The Brookings Institution.

Bloom, N., Reenen, J.V. (2010), Human Resource Management and Productivity, Cambridge: National Bureau of Economic Research.

Butler, D. (2006), Enterprise Planning and Development: Small Business Start-up, Survival and Development, Oxford: Elsevier Ltd.

Durowoju, S.T. (2014), "Roles of Entrepreneurship in small and medium enterprises development in Nigeria", Review of Public Administration and Management, Vol. 3, No 5, pp. 11-21.

Entrepreneurship Development for Competitive Small and Medium Enterprises: Report of the Asian Productivity Organization Survey on Entrepreneur Development for Competitive SMEs (2007), available at, http://www.apotokyo.org/00e-books/IS-26_SMEs/IS-26_SMEs.pdf, referred on 10/06/2017.

Eversole, R. (2004), Solving Poverty for Yourself: Microenterprise Development, Microfinance and Migration, available at, http:// www.cri.mq.edu.au/documents/mobile...rigid.../eversole.pdf, referred on 23/06/2017.

Goutam, S., Rishiraj, S. (2015), "Role of technology in entrepreneurial development: facilitating innovative ventures", International Journal of Emerging Technology and Advanced Engineering, Vol. 5, Special Issue 1, pp. 239-244. Hvostina, I.M. (2015), “Mechanism of management of enterprise development", Investment: Practice and Experience, No 1, pp. 30-33.

Klapper, L., El-Zoghbi, M., Hess, J. (2016), Achieving the Sustainable Development Goals: The Role of Financial Inclusion, Washington, DC: CGAP.

Kobernyk, I.V. (2012), "Peculiarities in development of enterprises' integrative processes", Actual Problems of Economics, Vol. 136, No 10, pp. 124-130.

Lopriore, M. (2009), "Supporting enterprise development and SME in Europe", EIPASCOPE, No 2, pp. 31-36.

Luiz, J. (2000), Small Business Development, Entrepreneurship and Expanding the Business Sector in a Developing Economy: The Case of South Africa, available at, https://econrsa.org/system/files/publications/policy_papers_ interest/pp14 interest.pdf, referred on 13/06/2017.

Nwankwo, F., Ewuim, N., Asoya, N.P. (2012), "Role of cooperatives in small and medium scale enterprises (SMEs) development in Nigeria: challenges and the way forward", African Research Review, Vol. 6 (4), No 27, pp. 140-156.

Oni, E.O., Daniya, A.A. (2012), "Development of small and medium scale enterprises: the role of Government and other financial institutions", Arabian Journal of Business and Management Review (OMAN Chapter), Vol. 1, No 7, pp. 16-29.

Pandya, A.M., Rao, N.V. (1998), "Diversification and firm performance: an empirical evaluation”, Journal of Financial and Strategic Decisions, Vol. 11, No 2, pp. 67-81.

Ricupero, R., Warner, A., Narain, S., Güttler, C., Kasekende, L., Zouari, M., Kloeppinger-Todd, R., Narasimham, R., Bays, J., Dunsby, B. (2001), Improving the Competitiveness of SMEs in Developing Countries. The Role of Finance to Enhance Enterprise Development, New York and Geneva: United Nations.

Sacala, I.S., Moisescu, M.A. (2014), “The development of enterprise systems based on cyberphysical systems principles", Romanian Statistical Review, No 4, pp. 29-39.

Satterthwaite, D. (1997), "Sustainable cities or cities that contribute to sustainable development", Urban Studies, Vol. 34, No 10, pp. 1667-1691.

Shchekovych, O.S., Khorolskyi,V.P., Khorolskyi, K.D. (2013), "Strategic management of development of pjscs within metinvest group", Actual Problems of Economics, Vol. 146, No 8, pp. 81-94.

Surugiu, I. (2012), "Integration of information technologies in enterprise application development", Database Systems Journal, Vol. III, No 1, pp. 21-32.

Taiwo, M.A., Ayodeji, A.M., Yusuf, B.A. (2012), "Impact of small and medium enterprises on economic growth and development", American Journal of Business and Management, Vol. 1, No 1, pp. 18-22.

Teece, D.J. (2010), “Business models, business strategy and innovation”, Long Range Planning, No 43, pp. 172-194. Unhelkar, B., Murugesan, S. (2010), "The enterprise mobile applications development framework", IT Professional, Vol. 12, Issue 3, pp. 33-39.

Varvarigos, D., Zakaria, I.Z. (2017), "Longevity, fertility and economic growth: do environmental factors matter?", Review of Development Economics, Vol. 21, Issue 1, pp. 43-66.

Zajarskas, R., Ruževičius, J. (2010), "Evaluation of the effectiveness of the quality management system of the service enterprise", Ekonomika ir Vadyba - Economics and Management, No 15, pp. 857-864. 